\title{
Predictors of mortality among elderly people living in a south Indian urban community; a 10/66 Dementia Research Group prospective population-based cohort study
}

\author{
AT Jotheeswaran ${ }^{1}$, Joseph D Williams ${ }^{1}$ and Martin J Prince*2
}

\begin{abstract}
Background: Eighty percent of deaths occur in low and middle income countries (LMIC), where chronic diseases are the leading cause. Most of these deaths are of older people, but there is little information on the extent, pattern and predictors of their mortality. We studied these among people aged 65 years and over living in urban catchment areas in Chennai, south India.

Methods: In a prospective population cohort study, 1005 participants were followed-up after three years. Baseline assessment included sociodemographic and socioeconomic characteristics, health behaviours, physical, mental and cognitive disorders, disability and subjective global health.

Results: At follow-up, 257 (25.6\%) were not traced. Baseline characteristics were similar to the 748 whose vital status was ascertained; 154 (20.6\%) had died. The mortality rate was 92.5/1000 per annum for men and 51.0/1000 per annum for women. Adjusting for age and sex, mortality was associated with older age, male sex, having no friends, physical inactivity, smaller arm circumference, dementia, depression, poor self-rated health and disability. A parsimonious model included, in order of aetiologic force, male sex, smaller arm circumference, age, disability, and dementia. The total population attributable risk fraction was 0.90 .

Conclusion: A balanced approach to prevention of chronic disease deaths requires some attention to proximal risk factors in older people. Smoking and obesity seem much less relevant than in younger people. Undernutrition is preventable. While dementia makes the largest contribution to disability and dependency, comorbidity is the rule, and more attention should be given to the chronic care needs of those affected, and their carers.
\end{abstract}

\section{Background}

Almost $80 \%$ of the world's deaths occur in low and middle income countries (LMIC), where estimation of cause of death is difficult, since most die at home without prior contact with health care professionals [1]. About 14.6 million deaths occurred in 2005 in the World Health Organisation's South-East Asia Region (SEARO) of which 6.8 million were among people aged 60 years and over [2]. Chronic diseases are now the leading cause of death in nearly all world regions, and older people contribute $72 \%$

\footnotetext{
* Correspondence: martin.prince@kcl.ac.uk

${ }^{2}$ Centre for Global Mental Health, Health Service and Population Research Department, Institute of Psychiatry, P060, De Crespigny Park, London SE5 8AF, UK

Full list of author information is available at the end of the article
}

of chronic disease deaths in LMIC [3]. Despite growing interest in chronic diseases in LMIC $[4,5]$, there is limited information available on their prevalence and impact among older people.

Factors associated with mortality in late-life can be subsumed into five domains; demographic variables; socioeconomic status; social relationships; health behaviours and health status. There are few studies of predictors of mortality among older people in LMIC [6-8], and none that have comprehensively addressed all of the relevant domains. In Wuhan, China independent effects of older age, male gender, lower education and serious illness were noted, the protective effect of education being more pronounced among women [6]. Neither socioeconomic 
factors, nor social support was associated with mortality in the final adjusted models. In Matlab, Bangladesh, mortality was ascertained through regular population censuses between 1982 and 1996 [8]. Mortality rates were stable among older people in contrast to the secular decline in younger age groups. Those with better education and higher socioeconomic status experienced lower mortality, as did those living with children. In a cohort study of socioeconomically disadvantaged older people in and around Asan City in South Korea (a recently developed country), male gender and poor self-rated health were the main predictors of mortality [7]. Ischaemic heart disease and stroke predicted mortality in men only.

Risk factors for mortality may differ between older and younger people. In India, analysis of data from the Indian National Family Household Survey of 1998-99, including over half a million participants of all ages in 26 states, revealed a considerable attenuation of the effects of standard-of-living on mortality in people aged 65 years and older, for whom caste (an index of status rather than material resources) seemed to be more relevant [9]. Nearly 150,000 participants aged 35 years and over were recruited in a prospective cohort study in Mumbai, followed up for six years to assess the effects of tobacco use and body mass index on mortality [10]. Undernutrition was a stronger risk factor for mortality than obesity. The increased mortality associated with tobacco use was mainly confined to smokers rather than those using smokeless products. Another report from the same study indicated that the relative risk for mortality associated with smoking cigarettes or bidi was substantially smaller in those aged 50 and over compared with younger participants [11]. In developed countries the association between mortality and lower socioeconomic status is well documented [12], including among older people [13,14]. However, some studies suggest that the socioeconomic gradient may be attenuated among older age groups [15]. Among older people evidence suggests increased mortality among those who smoke, have a poor quality diet, and are physically inactive [16]. In contrast to younger age groups, undernutrition $[17,18]$ is more consistently associated with mortality than obesity [19]. Depression and dementia have been extensively studied and are prominent independent predictors of mortality among older people. Meta-analyses suggest relative risks of 1.81 (95\% CI 1.58-2.07) for depression [20], and 2.63 (95\% CI 2.173.21) for dementia [21]. The effect of dementia seems to attenuate in the oldest old [22]. The effect sizes seem to be larger in LMIC; 5.16 in Brazil [23] and 2.83 in Nigeria [24]. There is an extensive literature attesting to the independent effects of lack of social relationships upon mortality among older people [25,26], with effect sizes comparable to health risk factors such as high blood pressure, smoking and obesity [27]. Functional and perceived aspects of social support may be even more salient to mortality risk [28]. Subjective well being and self-rated health were inversely associated with mortality among older people in several studies [29-31], although there are also negative reports $[32,33]$.

In summary, the large majority of deaths worldwide occur in LMIC, chronic diseases are now the leading cause of death in these regions, and most deaths from chronic diseases in LMIC are deaths of older people. Findings from studies carried out in developed countries suggest that predictors of mortality identified in younger age groups may not generalise to older people, and, of course, associations observed among older people in more developed settings may not generalise to LMIC. Identification of modifiable factors more proximally associated with mortality in late-life may lead to improvements in the quality as well as the quantity of life of older people. In this paper we assess the relative importance of sociodemographic characteristics, socioeconomic factors, health risk behaviours, physical, mental and cognitive morbidities, and the impact of these chronic conditions on health-related quality of life as predictors of mortality among people aged 65 years and over living in urban catchment areas in Chennai, south India.

\section{Methods}

\section{Settings and study design}

The 10/66 Dementia Research Group's (10/66 DRG) population-based studies of ageing and dementia in LMIC included an urban Indian site comprising five geographically defined catchment areas, Kandhanchavadi, Perungudi, Thoraipakkam, Palavakkam, and Kottivakkam in south Chennai. The design of the baseline and follow-up phases of the 10/66 DRG research program have been described in detail elsewhere [34]. The baseline survey comprised a comprehensive one phase assessment of all residents aged 65 years and over living in the defined catchment areas, identified by systematic door-knocking. In Chennai, 1005 participants were recruited into the baseline survey carried out between 2004 and 2006, representing $72 \%$ of all those eligible to participate. We carried out a follow-up of all baseline participants between December 2007 and July 2008, seeking to determine their vital status, and for those that had died, to determine their date of death and complete verbal autopsy interviews with relatives. Tracing was facilitated by the collection, at baseline of names and addresses of friends and family living in other households nearby. A minimum of three visits were made before a participant was declared to be untraceable. The baseline and follow-up studies were approved by King's College Research Ethics Committee and the Research Ethics Committee at Voluntary Health Services, Chennai, India, and participation was on the basis of informed signed consent. 


\section{Measures}

Full details of the assessments used in the baseline surveys are provided in another open access publication [34]. Here we describe only those assessments relevant to the analyses presented in this paper.

\section{Sociodemographic status}

Participants' ages were established during the baseline interview, from stated age, official documentation, informant report, and, in the case of discrepancy, age according to an event calendar. We also recorded the participant's gender, marital status and level of education. Socioeconomic position was ascertained according to the number of household assets (cars; television; fridge and/ or freezer; mains water; mains electricity; telephone; plumbed toilet; plumbed bathroom), declared income, and the presence or absence of food insecurity (sometimes or often having gone without food in the last month).

\section{Health status}

1) Diagnoses ascertained by clinical interview or examination

a) Dementia according to either our 10/66 dementia diagnosis algorithm (developed, calibrated and pre-validated cross-culturally in our 26 centre LMIC pilot study [35]) or Diagnostic and Statistical Manual, $4^{\text {th }}$ edition (DSM-IV) dementia criterion applied using an operationalised computer algorithm [36]. We assessed the severity of dementia (questionable, mild, moderate or severe) using the Clinical Dementia Rating Scale (CDR) [37]. Amnestic mild cognitive impairment (MCI) was defined as objective and subjective memory impairment, with no impairment in activities of daily living and not meeting the criteria for dementia [38].

b) Depression - ICD-10 depressive episode (mild, moderate or severe), ascertained using the Geriatric Mental State [39]. Those scoring four or more on the EURO-D depression scale [40], but not having symptoms meeting the criteria for ICD-10 depression were defined as having 'sub-syndromal depression'.

c) Hypertension - physical examination was performed to record systolic and diastolic resting blood pressure (average of two). Hypertension was defined as having been told by a doctor that you have hypertension and/or meeting European Society of Hypertension criteria (systolic blood pressure $>=140 \mathrm{~mm} \mathrm{Hg}$ and/or diastolic blood pressure $>=95 \mathrm{~mm} \mathrm{Hg}$ ).

d) Chronic obstructive pulmonary disease, defined as having a chronic cough, productive of sputum for three or more months

2) Self-reported diagnoses - stroke, angina and myocardial infarction ("have you ever been told by a doctor that you had a stroke/heart attack/angina/diabetes?")

3) Self-reported physical impairments - arthritis or rheumatism; eyesight problems; hearing difficulty or deafness; persistent cough; breathlessness, difficulty breathing or asthma; high blood pressure; heart trouble or angina; stomach or intestine problems; faints or blackouts; paralysis, weakness or loss of one leg or arm; skin disorders [41]. Each impairment was rated as present if it interfered with activities 'a little' or 'a lot'.

4) Disability - activity limitation and participation restriction measured by the WHODAS 2.0 [42], developed by the World Health Organization as a culture-fair assessment tool for use in cross-cultural comparative epidemiological and health services research.

5) Subjective global health rated on a five point scale very good/good/moderate/bad/very bad

\section{Lifestyle risk factors}

a) Alcohol use - patterns of drinking behaviour were ascertained from self-reports of units of alcohol consumed per week currently and before the age of 65 years. These data were used to identify three groups; long-term abstainers, previous drinkers who abstain after the age of 65 , and consistent drinkers. Those who answered yes to either or both of the questions 'Has there ever been a period of several years when you would have said that you were a heavy drinker?' and 'Have you ever had treatment or help for drinking from a doctor or some other agency?' were identified as heavy problem drinkers.

b) Tobacco use - we enquired after smoking behaviour (coded in this analysis as never, ex- and current smokers) and use of smokeless tobacco

c) Nutrition - reported current consumption of meat and fish; mid-upper arm circumference and waist circumference in centimetres

d) Underactivity - taking no walks of 500 metres or more in the past month

\section{Analyses}

All data was collected and entered into EPIDATA software and data analysis was performed using STATA version 10 . We calculated crude mortality rates per $1000 /$ year for each age group and both genders. India urban national mortality (1999) [43] and US national mortality rates (2005) [44] were used to calculate age and sex standardized mortality ratios (SMR) to compare the mortality experience of our cohort with that of these populations. $\mathrm{Chi}^{2}$ tests or t-tests were performed as appropriate to assess the statistical significance of differences in baseline characteristics between those participants whose vital status at follow-up was ascertained or unknown. The characteristics of those followed up successfully were then described by gender and by household assets. For the bivariate analyses of associations with mortality we report the cumulative mortality by exposure level for sociodemographic variables, lifestyle and other chronic disease risk factors, and health status (diagnoses, impairments and health related quality of life) with crude haz- 
ard ratios derived from Cox proportional hazard regression and logrank tests for statistical significance. We also report each of the hazard ratios adjusted for age and sex. Next we derived a parsimonious model for the prediction of mortality in the sample using forwards and backwards stepwise hazard regression procedures based on likelihood ratio testing at each step, initially entering all variables found to be significantly associated with mortality in either the crude or age and sex adjusted analyses. We then fitted the same model using Poisson regression to estimate the population attributable risk fraction (PARF) for each of the exposures in the parsimonious model, using the Stata aflogit command, which estimates the PARF from within a logistic regression framework, enabling confounding to be taken into account, and providing a robust estimation of the summary (combined) PARF for the full set of exposures in the model.

\section{Results}

\section{Sample characteristics}

We were able to determine the status of 748 (74.4\%) of the 1005 baseline participants, 594 (74.4\%) of whom were alive and $154(25.6 \%)$ had died. The remaining 257 could not be traced. This loss to follow-up was mainly accounted for by the construction of an information technology superhighway through the catchment area. There were no large or statistically significant differences in the sociodemographic, socioeconomic or health circumstances at baseline of those whose vital status was and was not ascertained at follow-up (Table 1), other than that those not followed-up had marginally smaller waist circumferences $(p=0.05)$. For those who were followed up, men were older than women, had more education, were more likely to be currently married, had more household assets, were more likely to smoke, to drink and to engage in problem drinking, and to report ischaemic heart disease (Table 1). However, women had worse selfreported health and higher disability scores. Also among those followed up, those with more household assets were older, and more likely to be male, better educated, and currently married. They were less likely to smoke. However, they had larger waists and upper arm circumferences, were more likely to be hypertensive, and to report diabetes, and three or more limiting chronic illnesses (Table 1).

\section{Mortality rate}

One hundred and fifty four deaths were recorded. For 34 of these the informant did not know the place of death, $102(85.0 \%)$ occurred at home and 18 (15.0\%) in hospital. For 83 (76.9\%) of the 108 deaths for which such information was available, no treatment of any kind was said to have been provided for the final illness. The overall mortality rate was $70.0 / 1000$ per annum, $92.5 / 1000$ pa for men and 51.0/1000 pa for women. The mortality rate increased steadily with age for both sexes (Table 2). After indirect standardization for age and gender, the observed mortality in our cohort was similar to that for urban India for women (SMR 103, 95\% CI 72 to 146) but higher than expected for men (SMR 158, 95\% CI 112 to 229). The observed mortality was higher than that for the USA among both women (SMR 198, 95\% CI 132 to 315) and men (SMR 231, 95\% CI 159 to 359).

\section{Bivariate analysis - baseline predictors of mortality}

Older age and male sex were associated with increased mortality with little mutual confounding (Table 3). Neither educational status, income, receipt of a pension, household assets, nor food insecurity predicted mortality. Marital status was not associated with mortality; however, there was some evidence that lacking friends or contact with friends was associated with an increased mortality risk.

There was an elevated mortality risk among ever smokers compared with those using smokeless tobacco and non-smokers, and a significant trend for an increasing risk with increasing levels of drinking from total abstinence through to heavy problem drinkers (Table 4). However, each of these associations attenuated, and was no longer statistically significant after controlling for age and sex. Physical inactivity conferred an increased risk. While dietary intake was not associated with mortality, there was a non-linear association between waist circumference and mortality with the increased risk confined to those in the second quarter of the population distribution, and a strong linear trend for increased risk associated with smaller mid upper arm circumferences.

Neither hypertension, ischaemic heart disease, stroke, diabetes, chronic obstructive pulmonary disease, or the number of limiting physical impairments was associated with mortality, either in the bivariate analysis, or after controlling for age and sex (Table 5). Indeed the only diagnoses or impairments associated with mortality were depression, and cognitive impairment and dementia, in both cases with increasing mortality risk with increasing levels of morbidity, independent of the effects of age and sex.

\section{A parsimonious model to predict mortality}

The final parsimonious Cox proportional hazards model included the effects of gender, age, dementia/cognitive impairment, and mid upper arm circumference (Model 1 - Table 6). According to likelihood ratio tests, no other variables could be added to the model with significant improvement (with the exception of WHODAS disability score) or removed from the model without significant deterioration in model fit. Inclusion of WHODAS disability score (Model 2) further improved the fit of the 
Table 1: Baseline sample characteristics by ascertainment of vital status at follow up, and by gender and household assets for those whose vital status was known.

\begin{tabular}{|c|c|c|c|c|c|c|c|c|c|}
\hline & \multicolumn{3}{|c|}{$\begin{array}{l}\text { Baseline sample characteristics by ascertainment } \\
\text { of vital status at follow up }\end{array}$} & \multicolumn{3}{|c|}{$\begin{array}{l}\text { Baseline sample characteristics by gender, } \\
\text { for those whose vital status was known. }\end{array}$} & \multicolumn{3}{|c|}{$\begin{array}{l}\text { Baseline sample characteristics by household assets, for } \\
\text { those whose vital status was known. }\end{array}$} \\
\hline & $\begin{array}{l}\text { Vital Status } \\
\text { known } \\
(n=748)\end{array}$ & $\begin{array}{l}\text { Vital Status not } \\
\text { known } \\
(\mathbf{n}=257)\end{array}$ & $X^{2}$, df (p-value) & $\begin{array}{l}\text { Female } \\
(n=422)\end{array}$ & $\begin{array}{l}\text { Male } \\
(\mathrm{n}=316)\end{array}$ & $x^{2}$, df (p-value) & $\begin{array}{l}\text { Fewest assets }-4 \text { or } \\
\text { fewer } \\
(n=459)\end{array}$ & $\begin{array}{l}\text { Most assets }-5 \text { or } \\
\text { more } \\
(n=289)\end{array}$ & $x^{2}$, df (p-value) \\
\hline Age - mean (SD) & $71.4(6.1)$ & $71.3(6.2)$ & $0.3^{1}, 1001(0.78)$ & $71.0(5.8)$ & $71.8(6.3)$ & $1.9^{1}, 644(0.05)$ & $70.9(5.9)$ & $72.2(6.2)$ & $2.9^{1}, 744(0.004)$ \\
\hline Female (\%) & 422 (57.2\%) & 149 (59.1\%) & $0.3,1(0.59)$ & - & - & - & $272(60.0 \%)$ & $150(52.6 \%)$ & $3.9,1,(0.05)$ \\
\hline Education & & & $0.0,1(0.98)$ & & & $71.9,1(<0.001)$ & & & $101.5,1,(<0.001)$ \\
\hline None & 314 (42.1\%) & $114(44.4 \%)$ & & $\begin{array}{l}240 \\
(57.0 \%)\end{array}$ & $72(22.8 \%)$ & & $245(53.5$ & 69 (24.0\%) & \\
\hline Some & 178 (23.9\%) & $56(21.8 \%)$ & & 78 (18.5\%) & $98(31.0 \%)$ & & 111 (24.3\%) & 67 (23.3\%) & \\
\hline Primary & 160 (21.4\%) & $52(20.2 \%)$ & & 74 (17.6\%) & $84(26.6 \%)$ & & 77 (16.8\%) & $83(28.8 \%)$ & \\
\hline Secondary & $66(8.8 \%)$ & $21(8.2 \%)$ & & $20(4.8 \%)$ & $44(13.9 \%)$ & & $23(5.0 \%)$ & $43(14.9 \%)$ & \\
\hline Tertiary & $28(3.8 \%)$ & $14(5.4 \%)$ & & $9(2.1 \%)$ & $18(5.7 \%)$ & & $2(0.4 \%)$ & $26(9.0 \%)$ & \\
\hline Marital status & & & $6.0,3(0.11)$ & & & $184.0,3(<0.001)$ & & & $10.1,3,(0.02)$ \\
\hline Never married & 12 (1.6\%) & $9(3.5 \%)$ & & $5(1.2 \%)$ & $6(1.9 \%)$ & & $8(1.7 \%)$ & $4(1.4 \%)$ & \\
\hline Married & 382 (51.1\%) & $141(55.3 \%)$ & & $\begin{array}{l}125 \\
(29.6 \%)\end{array}$ & $\begin{array}{l}250 \\
(79.1 \%)\end{array}$ & & $215(46.8 \%)$ & 167 (58.0\%) & \\
\hline Widowed & 330 (44.2\%) & $96(37.6 \%)$ & & $\begin{array}{l}275 \\
(65.2 \%)\end{array}$ & $54(17.1 \%)$ & & $218(47.5 \%)$ & $112(38.9 \%)$ & \\
\hline Divorced/separated & $23(3.1 \%)$ & $9(3.5 \%)$ & & $17(4.0 \%)$ & $6(1.9 \%)$ & & $18(3.9 \%)$ & $5(1.7 \%)$ & \\
\hline
\end{tabular}


Table 1: Baseline sample characteristics by ascertainment of vital status at follow up, and by gender and household assets for those whose vital status was known.

\begin{tabular}{|c|c|c|c|c|c|c|c|c|c|}
\hline \multirow{2}{*}{$\begin{array}{l}\text { Assets } \\
1^{\text {st }} \text { quarter }\end{array}$} & \multirow[b]{2}{*}{$90(12.0 \%)$} & \multirow[b]{2}{*}{42 (16.5\%) } & \multirow[t]{2}{*}{$0.86,1(0.35)$} & \multirow[b]{2}{*}{$52(12.4 \%)$} & \multirow[b]{2}{*}{37 (11.7\%) } & \multicolumn{2}{|l|}{$5.0,1(0.03)$} & \multirow[b]{2}{*}{-} & \\
\hline & & & & & & & - & & \\
\hline $2^{\text {nd }}$ quarter & 368 (49.3\%) & $122(48.0 \%)$ & & $\begin{array}{l}219 \\
(52.0 \%)\end{array}$ & $\begin{array}{l}144 \\
(45.6 \%)\end{array}$ & & - & - & \\
\hline $3^{\text {rd }}$ quarter & 105 (14.1\%) & $25(9.8 \%)$ & & $63(15.0 \%)$ & $42(13.3 \%)$ & & - & - & \\
\hline $4^{\text {th }}$ quarter & 184 (24.6\%) & 65 (25.6\%) & & 67 (20.7\%) & 93 (29.4\%) & & - & - & \\
\hline Smoking: & & & $0.9,2(0.65)$ & & & $161.5,2(<0.001)$ & & & $19.2,2,(<0.001)$ \\
\hline Never smoker & 548 (73.8\%) & $182(71.7 \%)$ & & $\begin{array}{l}381 \\
(90.9 \%)\end{array}$ & $\begin{array}{l}162 \\
(51.3 \%)\end{array}$ & & $316(69.1 \%)$ & 232 (81.1\%) & \\
\hline Ex-smoker & 65 (8.7\%) & $21(8.3 \%)$ & & $0(0.0 \%)$ & 62 (19.6\%) & & 39 (8.5\%) & $26(9.1 \%)$ & \\
\hline Current smoker & $130(17.5 \%)$ & $51(20.1 \%)$ & & $38(9.1 \%)$ & 92 (29.1\%) & & $102(22.3 \%)$ & $28(9.8 \%)$ & \\
\hline Alcohol use & & & $0.4,1(0.51)$ & & & $102.1,1(<0.001)$ & & & $0.6,1,(0.43)$ \\
\hline Always abstinent & 559 (83.9\%) & 174 (83.7\%) & & $\begin{array}{l}364 \\
(99.2 \%)\end{array}$ & $\begin{array}{l}194 \\
(65.1 \%)\end{array}$ & & 338 (83.0\%) & $221(85.3 \%)$ & \\
\hline $\begin{array}{l}\text { Moderate drinker, } \\
\text { abstinent after the age } \\
\text { of } 65\end{array}$ & $45(6.8 \%)$ & 15 (7.2\%) & & $2(0.5 \%)$ & $43(14.4 \%)$ & & $29(7.1 \%)$ & $16(6.2 \%)$ & \\
\hline $\begin{array}{l}\text { Consistent moderate } \\
\text { drinker }\end{array}$ & $26(3.9 \%)$ & $13(6.3 \%)$ & & $0(0.0 \%)$ & $26(8.7 \%)$ & & $16(3.9 \%)$ & $10(3.9 \%)$ & \\
\hline $\begin{array}{l}\text { Heavy drinker and/or } \\
\text { sought treatment }\end{array}$ & $36(5.4 \%)$ & $6(2.9 \%)$ & & $1(0.3 \%)$ & 35 (11.7\%) & & 24 (5.9\%) & $12(4.6 \%)$ & \\
\hline Physically inactive & $160(21.5 \%)$ & $58(23.0 \%)$ & $0.3,1(0.61)$ & $\begin{array}{l}101 \\
(23.9 \%)\end{array}$ & $58(18.4 \%)$ & $3.3,1(0.07)$ & $107(23.4 \%)$ & $53(18.5 \%)$ & $2.5,1,(0.11)$ \\
\hline
\end{tabular}


Table 1: Baseline sample characteristics by ascertainment of vital status at follow up, and by gender and household assets for those whose vital status was known.

\begin{tabular}{|c|c|c|c|c|c|c|c|c|c|}
\hline $\begin{array}{l}\text { Waist circum } \\
\text { ference - mean (SD) }\end{array}$ & $83.2(11.1)$ & $81.5(11.5)$ & $2.0^{1}, 987(0.05)$ & $82.5(10.9)$ & $84.0(11.1)$ & $1.71,725(0.08)$ & $81.4(10.9)$ & $85.8(11.2)$ & $5.2^{1}, 744,(<0.001)$ \\
\hline $\begin{array}{l}\text { Arm circum } \\
\text { ference - mean (SD) }\end{array}$ & $23.8(4.2)$ & $23.3(3.8)$ & $1.61,991(0.11)$ & $\begin{array}{l}23.4 \\
(3.9)\end{array}$ & $24.2(3.9)$ & $2.8^{1}, 728(0.006)$ & $22.8(3.4)$ & $25.3(4.8)$ & $8.4^{1}, 744,(<0.001)$ \\
\hline ICD-10 Depression & $25(3.3 \%)$ & $14(5.4 \%)$ & $2.3,1(0.13)$ & $13(3.1 \%)$ & $12(3.8 \%)$ & $0.3,1(0.59)$ & $18(3.9 \%)$ & $7(2.4 \%)$ & $1.2,1,(0.27)$ \\
\hline Dementia & $54(7.2 \%)$ & $21(8.2 \%)$ & $0.3,1(0.62)$ & $33(7.8 \%)$ & $21(6.6 \%)$ & $0.4,1(0.54)$ & $37(8.1 \%)$ & 17 (5.9\%) & $1.3,1,(0.26)$ \\
\hline Hypertension & $454(60.7 \%)$ & $144(56.0 \%)$ & $1.7,1(0.19)$ & $\begin{array}{l}261 \\
(61.8 \%)\end{array}$ & $\begin{array}{l}188 \\
(59.5 \%)\end{array}$ & $0.4,1(0.52)$ & $257(56.0 \%)$ & $197(68.2 \%)$ & $11.0,1,(0.001)$ \\
\hline Stroke & $17(2.3 \%)$ & $3(1.2 \%)$ & $1.2,1(0.27)$ & $6(1.4 \%)$ & $9(2.8 \%)$ & $1.8,1(0.17)$ & $9(2.0 \%)$ & $8(2.8 \%)$ & $0.5,1,(0.47)$ \\
\hline Ischaemic heart disease & $38(5.1 \%)$ & $11(4.3 \%)$ & $0.3,1(0.61)$ & $14(3.3 \%)$ & $24(7.6 \%)$ & $6.8,1(0.009)$ & $19(4.1 \%)$ & $19(6.6 \%)$ & $2.2,1,(0.14)$ \\
\hline Diabetes & $92(12.3 \%)$ & $29(11.3 \%)$ & $0.2,1(0.66)$ & $51(12.1 \%)$ & $40(12.7 \%)$ & $0.1,1(0.81)$ & $46(10.0 \%)$ & $46(16.0 \%)$ & $5.8,1,(0.02)$ \\
\hline $\begin{array}{l}\text { Three or more limiting } \\
\text { physical impairments }\end{array}$ & $30(4.0 \%)$ & $11(4.3 \%)$ & $0.0,1(0.85)$ & $16(3.8 \%)$ & $13(4.1 \%)$ & $0.1,1(0.82)$ & $10(2.2 \%)$ & $20(6.9 \%)$ & $10.4,1,(0.001)$ \\
\hline Self-rated health & & & $2.4,1(0.12)$ & & & $14.3,1(<0.001)$ & & & $0.0,1,0.95$ \\
\hline Very good & 321 (43.0\%) & 97 (37.9\%) & & $\begin{array}{l}165 \\
(39.1 \%)\end{array}$ & $\begin{array}{l}153 \\
(48.4 \%)\end{array}$ & & $197(42.9 \%)$ & $124(43.1 \%)$ & \\
\hline Good & $269(36.0 \%)$ & $98(38.3 \%)$ & & $\begin{array}{l}149 \\
(35.3 \%)\end{array}$ & $\begin{array}{l}115 \\
(36.4 \%)\end{array}$ & & 165 (35.9\%) & $104(36.1 \%)$ & \\
\hline Moderate & $126(16.9 \%)$ & $46(18.0 \%)$ & & $83(19.7 \%)$ & $43(13.6 \%)$ & & $78(17.0 \%)$ & $48(16.7 \%)$ & \\
\hline Bad or very bad & $31(4.1 \%)$ & 15 (5.9\%) & & $25(5.9 \%)$ & $5(1.6 \%)$ & & $19(4.1 \%)$ & $12(4.2 \%)$ & \\
\hline Disability - mean (SD) & $10.7(15.2)$ & $10.1(16.2)$ & $0.5^{1}, 999(0.61)$ & $12.1(16.1)$ & $8.6(13.1)$ & & $\begin{array}{l}10.9 \\
(15.7)\end{array}$ & $\begin{array}{l}10.4 \\
(14.3)\end{array}$ & $0.4^{1}, 744,(0.70)$ \\
\hline
\end{tabular}

1. F-value from t-test 
Table 2: Crude mortality rates, per 1000 person years, by age and sex

\begin{tabular}{|c|c|c|c|c|c|c|c|c|c|}
\hline \multirow{2}{*}{$\begin{array}{l}\text { Sex } \\
(10 M V 1) \\
\text { Age } \\
\left(3 M^{1}\right)\end{array}$} & \multicolumn{3}{|l|}{ Women } & \multicolumn{3}{|l|}{ Men } & \multicolumn{3}{|c|}{ Both sexes combined } \\
\hline & Deaths & $\begin{array}{l}\text { Person } \\
\text { years }\end{array}$ & $\begin{array}{l}\text { Mortality rate (per } \\
1000 \text { person } \\
\text { years) }\end{array}$ & Deaths & $\begin{array}{l}\text { Person } \\
\text { years }\end{array}$ & $\begin{array}{l}\text { Mortality rate } \\
\text { (per } 1000 \\
\text { person years) }\end{array}$ & Deaths & $\begin{array}{l}\text { Person } \\
\text { years }\end{array}$ & $\begin{array}{l}\text { Mortality rate } \\
\text { (per } 1000 \text { person } \\
\text { years) }\end{array}$ \\
\hline $65-69$ & 19 & 561.1 & 33.9 & 21 & 388.6 & 54.0 & 42 & 960.7 & 43.7 \\
\hline $70-74$ & 21 & 421.5 & 49.8 & 22 & 247.5 & 88.9 & 44 & 680.1 & 64.7 \\
\hline $75-79$ & 11 & 148.6 & 74.0 & 19 & 163.7 & 116.1 & 30 & 312.3 & 96.1 \\
\hline $80+$ & 13 & 137.0 & 94.9 & 21 & 94.8 & 221.5 & 37 & 238.2 & 155.3 \\
\hline $\begin{array}{l}\text { All ages } \\
\text { combined }\end{array}$ & 65 & 1274.4 & 51.0 & 83 & 897.3 & 92.5 & 154 & 2200.2 & 70.0 \\
\hline
\end{tabular}

model, but with some attenuation of the effect of cognitive impairment/dementia. Both models met proportional hazards assumptions, both with respect to the global test (Table 6) and individual covariates. In terms of population attributable risk fractions the predictors of mortality with the strongest aetiologic force were, in descending order, male sex, mid upper arm circumference, age, disability, and cognitive impairment/dementia. Both models were highly predictive of future mortality; for model 2, including the effects of disability, the total adjusted PARF was 0.90 (95\% CI 0.79-0.95)

\section{Mortality and gender}

Given the strong observed associations in our sample between sex and sociodemographic factors (age, education, assets, marital status) health related factors (smoking, alcohol use, ischaemic heart disease) and health related quality of life (subjective global health rating and disability), we decided to assess the extent to which increased mortality observed among men (crude hazard ratio $1.82,95 \% \mathrm{CI}, 1.32-2.52$ ) might be mediated through any of these variables. The effect of male gender did not attenuate after adjusting for age (1.80), education (2.04), assets (1.84), marital status (2.04), nor for all of these sociodemographic variables simultaneously (1.90). Neither did the effect attenuate after controlling for smoking (1.80) or ischaemic heart disease (1.84); some attenuation was seen after adjusting for alcohol use (1.57), and for all of these health variables simultaneously (1.60). Neither subjective global health rating (1.98), disability (2.11) nor both variables together (2.15) attenuated the effect of male sex. The effect of male sex in the final fully adjusted model, including all of the above mentioned sociodemo- graphic, health and health related quality of life variables was 2.05 (95\% CI, 1.37-3.32).

\section{Discussion}

The strengths of this study are; first the focus upon older people, among whom, in India and other LMIC there are few data on the extent, pattern and predictors of mortality; and second the relatively comprehensive coverage of potentially relevant exposures at baseline including sociodemographic and socioeconomic characteristics, health behaviours, a range of physical, mental and cognitive chronic health conditions and their consequences (disability and subjective global health ratings). The main limitations are the relatively small sample size, the loss to follow up, and the fact that not all chronic diseases were ascertained with equivalent rigour. Reassuringly, there were almost no statistically significant differences between those for whom vital status was and was not ascertained at follow-up, consistent with our impression that most failures to trace baseline participants were accounted for by the fairly random demolition of homes to make way for an IT superhighway.

The overall mortality rate of 70/1000 per year was slightly higher than national estimates of mortality for urban populations, accounted for entirely by an excess of male mortality in our cohort. The fact that $85 \%$ of deaths occurred at home, and $77 \%$ received no medical attention for their final illness underlines the inherent difficulty in estimating accurate mortality rates among older people using official registration procedures. The effect size for male gender in our study (HR 2.1, 95\% CI 1.5-3.0 in the final model) was also much larger than that reported for those aged 65 and over in the Indian National Family 
Table 3: Mortality by baseline sociodemographic characteristics:

\begin{tabular}{|c|c|c|c|c|}
\hline Socio demographic characteristic & $\begin{array}{l}\text { Cumulative } \\
\text { mortality }\end{array}$ & $\begin{array}{l}\text { Hazard ratio } \\
(95 \% \mathrm{Cl})\end{array}$ & $\begin{array}{l}\text { Hazard ratio }(95 \% \mathrm{Cl}) \\
\text { Adjusted for Age and sex }\end{array}$ & Log-rank test \\
\hline Age group ( $\left.M{ }^{1}=2\right)$ & & & & $x^{2}=38.3, d f(3), p=<0.001$ \\
\hline $65-69$ & $42 / 268(13.5 \%)$ & Ref & Ref & \\
\hline 70-74 & $44 / 231(19.0 \%)$ & $1.5(0.9-2.2)$ & $1.5(1.0-2.3)$ & \\
\hline $75-79$ & $30 / 112(26.8 \%)$ & $2.3(1.4-3.7)$ & $2.2(1.4-3.6)$ & \\
\hline $80+$ & $37 / 92(40.2 \%)$ & $3.5(2.2-5.5)$ & $3.5(2.2-5.5)$ & \\
\hline $\operatorname{Sex}(M V=10)$ & & & & $X^{2}=13.9, d f(1), p=0.0002$ \\
\hline Female & $65 / 422(15.4 \%)$ & Ref & Ref & \\
\hline Male & $83 / 316(26.3 \%)$ & $1.8(1.3-2.5)$ & $1.8(1.3-2.5)$ & \\
\hline Marital status (MV = 1 ) & & & & $X^{2}=1.73, \mathrm{df}(3), p=0.63$ \\
\hline Never married & $4 / 12(33.3 \%)$ & Ref & Ref & \\
\hline Married & $87 / 382(22.7 \%)$ & $0.5(0.2-1.6)$ & $0.5(0.1-1.4)$ & \\
\hline Widowed & $59 / 330(17.8 \%)$ & $0.5(0.2-1.5)$ & $0.6(0.2-1.8)$ & \\
\hline Divorced/separated & $4 / 23(17.4 \%)$ & $0.4(0.1-1.7)$ & $0.4(0.1-1.8)$ & \\
\hline Living arrangements $(\mathrm{MV}=0)$ & & & & $X^{2}=0.2, d f(1), p=0.66$ \\
\hline Alone or with spouse only & $22 / 117(18.8 \%)$ & $0.9(0.5-1.4)$ & $0.9(0.5-1.4)$ & \\
\hline With others & 132/631 (20.9\%) & Ref & Ref & \\
\hline Educational level (MV = 2) & & & & $X^{2}=0.0 \mathrm{df}(1), p=0.99$ \\
\hline None & $68 / 314(21.6 \%)$ & Ref & Ref & \\
\hline Some & $33 / 178(18.5 \%)$ & $0.9(0.6-1.4)$ & $0.7(0.5-1.2)$ & \\
\hline Primary & $35 / 160(21.8 \%)$ & $1.0(0.7-1.6)$ & $0.8(0.5-1.2)$ & \\
\hline Secondary \& Higher & $17 / 94(18.1 \%)$ & $0.9(0.5-1.6)$ & $0.6(0.3-1.1)$ & \\
\hline Have friends $(M V=2)$ & & & & $X^{2}=4.70, d f(1), p=0.03$ \\
\hline Yes & $66 / 382(17.2 \%)$ & Ref & Ref & \\
\hline No & $87 / 364(24 \%)$ & $1.4(1.0-1.9)$ & $1.3(0.9-1.8)$ & \\
\hline
\end{tabular}


Table 3: Mortality by baseline sociodemographic characteristics: (Continued)

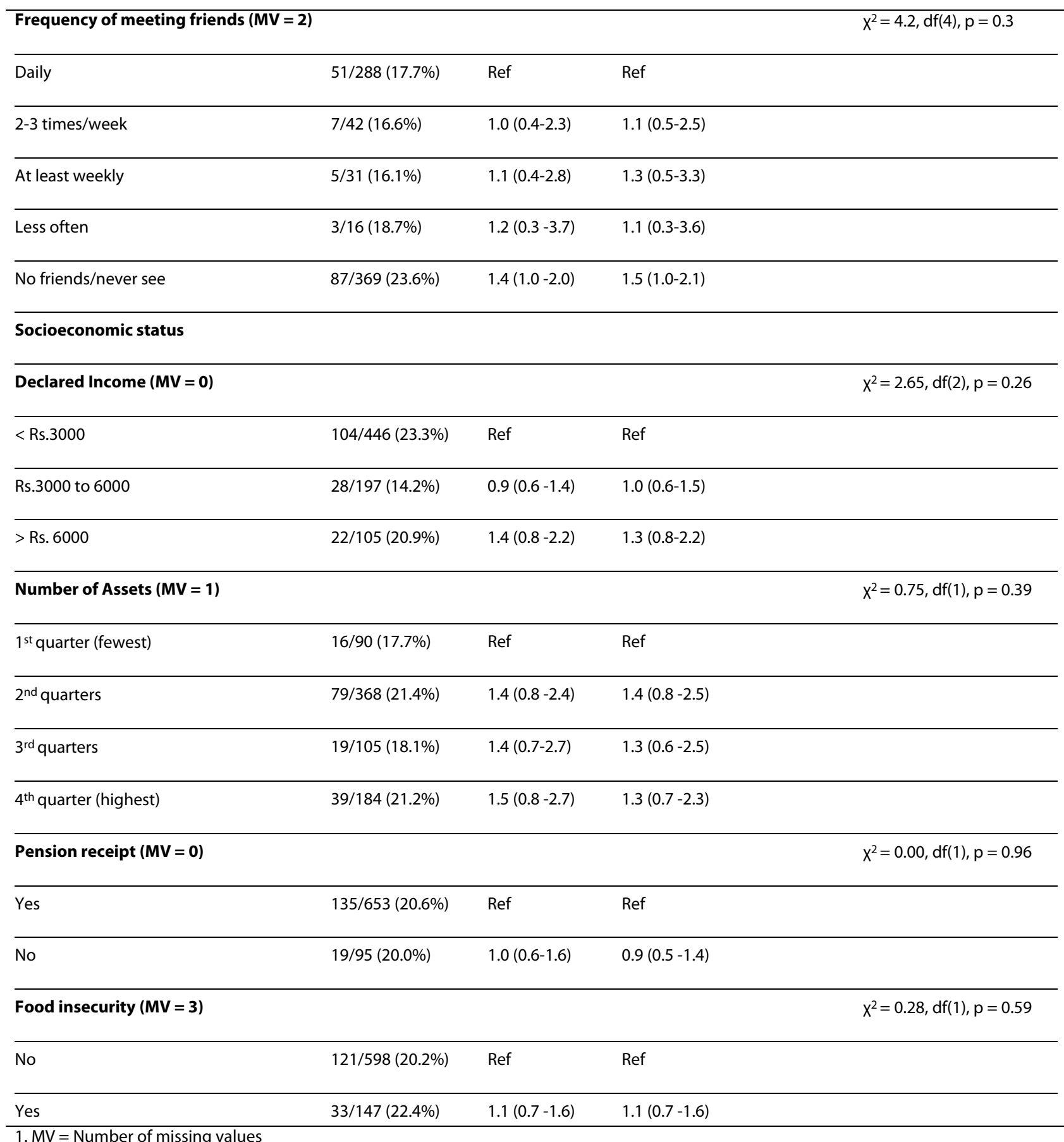

Health Survey (OR 1.09, 95\% CI 1.01-1.15) [9], and in a previous large verbal autopsy study in Chennai $(\mathrm{M} / \mathrm{F}$ mortality ratio 1.28 for those aged $65-69,1.15$ age $70-74$ and 0.80 for those aged 75 years and over) [45]. Our estimate is more consistent with those reported from developed countries, and may suggest a selective under- registration of deaths among older men in some previous Indian studies.

Our results show that male sex, mid upper arm circumference, age, disability and cognitive impairment/dementia are the parsimonious predictors of mortality among older people in Chennai, which, assuming causal relation- 
Table 4: Mortality by lifestyle and other chronic disease risk factors

\begin{tabular}{llll}
\hline Life style factors & Cumulative mortality & Hazard ratio (95\%Cl) & $\begin{array}{l}\text { Hazard ratio }(95 \% \mathrm{Cl}) \\
\text { Adjusted for Age + } \\
\text { Gender }\end{array}$ \\
& & Log-rank test
\end{tabular}

$\begin{array}{ll}\text { Smoking }\left(M V^{1}=5\right) & X^{2}=7.04 \\ d f(2), p=0.02\end{array}$

\begin{tabular}{|c|c|c|c|c|}
\hline Never smoked & $102 / 548(18.6 \%)$ & Ref & Ref & \\
\hline Smokeless tobacco & $7 / 36(19.4 \%)$ & $0.9(0.4-2.0)$ & $0.7(0.3-1.7)$ & \\
\hline Smoking tobacco & $43 / 158(27.1 \%)$ & $1.6(1.1-2.2)$ & $1.1(0.7-1.6)$ & \\
\hline Alcohol use (MV = 82) & & & & $\begin{array}{l}x^{2}=5.65 \\
d f(1), p=0.02\end{array}$ \\
\hline Always abstinent & $108 / 559(19.3 \%)$ & Ref & Ref & \\
\hline $\begin{array}{l}\text { Moderate drinker, abstinent } \\
\text { after the age of } 65\end{array}$ & $8 / 45$ (17.9\%) & $0.8(0.4-1.7)$ & $0.6(0.3-1.2)$ & \\
\hline $\begin{array}{l}\text { Consistent moderate } \\
\text { drinker }\end{array}$ & $7 / 26(26.9 \%)$ & $1.4(0.7-3.1)$ & $1.0(0.4-2.1)$ & \\
\hline $\begin{array}{l}\text { Heavy drinker and/or } \\
\text { sought treatment for } \\
\text { alcohol problem }\end{array}$ & $14 / 36(38.9 \%)$ & $2.1(1.2-3.7)$ & $1.4(0.8-2.6)$ & \\
\hline
\end{tabular}

\section{Diet and nutrition}

Fish in diet $(M V=3)$

$X^{2}=0.77$

df (2), $p=0.68$

\begin{tabular}{|c|c|c|c|c|}
\hline Never & $26 / 139$ (18.7\%) & Ref & Ref & \\
\hline Some days & 103/503 (20.4\%) & $1.0(0.7-1.6)$ & $1.1(0.7-1.7)$ & \\
\hline Most of the days & $25 / 103(24.2 \%)$ & $1.2(0.7-2.2)$ & $1.3(0.7-2.3)$ & \\
\hline Meat in diet $(M V=2)$ & & & & $\begin{array}{l}x^{2}=0.07 \\
d f(2), p=0.96\end{array}$ \\
\hline Never & $34 / 180(18.8 \%)$ & Ref & & \\
\hline Some days & 100/474 (21.1\%) & $1.0(0.7-1.5)$ & $1.0(0.7-1.5)$ & \\
\hline Most of the days & $20 / 92(21.7 \%)$ & $1.0(0.5-1.7)$ & $1.0(0.6-1.8)$ & \\
\hline
\end{tabular}


Table 4: Mortality by lifestyle and other chronic disease risk factors (Continued)

\begin{tabular}{|c|c|c|c|c|}
\hline $\begin{array}{l}\text { Physical activity } \\
(M V=3)\end{array}$ & & & & $\begin{array}{l}X^{2}=7.32 \\
d f(1), p=0.006\end{array}$ \\
\hline Yes & $124 / 637(19.4 \%)$ & Ref & Ref & \\
\hline No & $28 / 107$ (28.0\%) & $1.7(1.1-2.5)$ & $1.5(1.0-2.3)$ & \\
\hline $\begin{array}{l}\text { Arm circumference } \\
(\mathrm{MV}=9)\end{array}$ & & & & $\begin{array}{l}X^{2}=10.1 \\
d f(1), p=0.001\end{array}$ \\
\hline $1^{\text {st }}$ quarter & $59 / 200(29.5 \%)$ & Ref & Ref & \\
\hline $2^{\text {nd }}$ quarter & $38 / 185$ (20.5\%) & $0.6(0.4-1.0)$ & $0.6(0.4-0.9)$ & \\
\hline $3^{\text {rd }}$ quarter & $25 / 156(16.0 \%)$ & $0.5(0.3-0.9)$ & $0.5(0.3-0.9)$ & \\
\hline $4^{\text {th }}$ quarter & $30 / 198(15.1 \%)$ & $0.5(0.3-0.7)$ & $0.4(0.3-0.7)$ & \\
\hline Per centimetre & - & $0.90(0.85-0.94)$ & $0.89(0.84-0.94)$ & \\
\hline $\begin{array}{l}\text { Waist circumference } \\
(M V=12)\end{array}$ & & & & $\begin{array}{l}x^{2}=14.6 \\
d f(3), p=0.002\end{array}$ \\
\hline $1^{\text {st }}$ quarter & $33 / 174(19.0 \%)$ & (Ref) & (Ref) & \\
\hline $2^{\text {nd }}$ quarter & $58 / 189(30.7 \%)$ & $1.8(1.2-2.8)$ & $1.7(1.1-2.7)$ & \\
\hline $3^{\text {rd }}$ quarter & $31 / 187(16.6 \%)$ & $0.9(0.5-1.5)$ & $0.9(0.5-1.5)$ & \\
\hline $4^{\text {th }}$ quarter & $29 / 186(15.6 \%)$ & $0.9(0.5-1.4)$ & $0.9(0.5-1.4)$ & \\
\hline
\end{tabular}

1. MV = Number of missing values

ships free of confounding account collectively for $90 \%$ of the observed mortality in the cohort under study. The impressive predictiveness of this model would seem to allow little scope for the salience to mortality of other unobserved or observed but misclassified factors. However,

1) it is likely that we underascertained diabetes, stroke and ischaemic heart disease at baseline because of reliance on self-reported clinical diagnoses, which would be biased because of low levels of help-seeking, low detection, and unclear communication of diagnoses to patients. We may therefore have underestimated the effect of some or all of these chronic physical health conditions upon mortality, some of which may have been captured instead in the sizeable independent effect of self-reported disability.
2) while age and sex cannot be modified it would be important, given the size of their effects, to understand better the mechanisms through which these are mediated. The effect of sex was not explained by any of the many compositional differences between men and women observed in our study, with the partial exception of lifelong and heavy problem drinking, which was more or less a male preserve, and which, upon adjustment, attenuated slightly the effect of male sex on mortality.

The absence of certain associations, consistently observed among younger people and in developed countries was striking. We failed to observe any effects of socioeconomic status, assessed in terms of income, assets and food insecurity, upon mortality. This finding is consistent with the absence of a socioeconomic gradient for mortality among older people in the Indian National 
Table 5: Mortality by baseline health status - diagnoses and impairments

\begin{tabular}{llll}
\hline $\begin{array}{l}\text { Morbidities } \\
\text { \& Life style }\end{array}$ & Cumulative mortality & Hazard ratio $(95 \% \mathrm{Cl})$ & $\begin{array}{l}\text { Hazard ratio }(95 \% \mathrm{Cl}) \\
\text { Adjusted for Age + } \\
\text { Gender }\end{array}$
\end{tabular}

\section{Survey clinical diagnosis}

\section{Dementia $\left(M^{1} \mathbf{1}=0\right)$}

$X^{2}=25.0$,

$\mathrm{df}(1) p=<0.001$

\begin{tabular}{llll}
\hline No & $129 / 694(18.6 \%)$ & Ref & Ref \\
\hline Yes & $25 / 54(46.3 \%)$ & $2.8(1.8-4.3)$ & $2.3(1.5-3.7)$
\end{tabular}

\section{Cognitive Impairment}

$(M V=0)$
$X^{2}=37.4$,

$\operatorname{df}(1), p=<0.001$

\begin{tabular}{llll}
\hline Cognitively healthy & $122 / 672(18.2 \%)$ & Ref & Ref \\
\hline $\begin{array}{l}\text { Mild Cognitive } \\
\text { Impairment }\end{array}$ & $7 / 26(26.9 \%)$ & $1.9(0.9-4.0)$ & $1.9(0.9-4.2)$ \\
\hline $\begin{array}{l}\text { CDR questionable } \\
\text { dementia }\end{array}$ & $15 / 34(44.1 \%)$ & $2.8(1.6-4.8)$ & $2.1(1.2-3.7)$ \\
\hline $\begin{array}{l}\text { CDR mild moderate \& } \\
\text { severe dementia }\end{array}$ & $10 / 16(62.5 \%)$ & $5.1(2.7-9.7)$ & $4.1(2.1-7.9)$
\end{tabular}

severe dementia

Depression $(\mathrm{MV}=0)$

$X^{2}=9.2$

$\mathrm{df}(1), p=0.002$

\begin{tabular}{llll}
\hline No depression & $81 / 446(18.2 \%)$ & Ref & Ref \\
\hline Depression subcase & $65 / 277(23.5 \%)$ & $1.5(1.1-2.2)$ & $1.6(1.2-2.3)$ \\
\hline ICD 10 depression case & $8 / 25(32.0 \%)$ & $2.2(1.1-4.5)$ & $2.1(1.0-4.3)$
\end{tabular}

Hypertension $(\mathrm{MV}=\mathbf{0})$

$X^{2}=0.8$,

$\mathrm{df}(1), p=0.59$

\begin{tabular}{llll}
\hline No & $69 / 294(23.4 \%)$ & Ref & Ref \\
\hline Yes & $85 / 454(18.7 \%)$ & $0.8(0.6-1.1)$ & $0.9(0.6-1.3)$ \\
\hline $\begin{array}{l}\text { Chronic Obstructive } \\
\text { Pulmonary Disease }\end{array}$ & & & $X^{2}=0.20$, \\
df $(1), p=0.65$
\end{tabular}

Self-reported physician

diagnosis 
Table 5: Mortality by baseline health status - diagnoses and impairments (Continued)

\begin{tabular}{|c|c|c|c|c|}
\hline Stroke $(M V=1)$ & & & & $X^{2}=1.87$ \\
\hline No & 149/731 (20.3\%) & Ref & Ref & \\
\hline Yes & $5 / 16(31.2 \%)$ & $1.8(0.7-4.5)$ & $1.6(0.6-4.1)$ & \\
\hline Diabetes $(M V=1)$ & & & & $\begin{array}{l}X^{2}=0.57 \\
d f(1), p=0.44\end{array}$ \\
\hline No & $138 / 655$ (21.0\%) & Ref & Ref & \\
\hline Yes & 16/92 (17.4\%) & $0.8(0.4-1.3)$ & $0.7(0.4-1.3)$ & \\
\hline $\begin{array}{l}\text { Ischaemic heart disease } \\
(M V=1)\end{array}$ & & & & $\begin{array}{l}X^{2}=0.08 \\
d f(1), p=0.78\end{array}$ \\
\hline No & $147 / 709$ (20.7\%) & Ref & Ref & \\
\hline Yes & $7 / 38$ (18.4\%) & $0.8(0.4-1.9)$ & $0.9(0.4-1.9)$ & \\
\hline $\begin{array}{l}\text { Number of self-reported } \\
\text { limiting physical } \\
\text { impairments }(M V=1)\end{array}$ & & & & $\begin{array}{l}x^{2}=3.65 \\
d f(2), p=0.16\end{array}$ \\
\hline None & $89 / 479$ (18.5\%) & Ref & Ref & \\
\hline One or two & $58 / 238(24.3 \%)$ & $1.3(0.9-1.9)$ & $1.4(1.0-1.9)$ & \\
\hline More than three & $7 / 30$ (23.3\%) & $1.3(0.6-2.8)$ & $1.1(0.4-2.6)$ & \\
\hline $\begin{array}{l}\text { Time taken to walk } 10 \\
\text { metres (per second) } \\
(M V=6)\end{array}$ & - & $1.02(1.01-1.03)$ & $1.02(1.01-1.04)$ & $\begin{array}{l}X^{2}=5.5 \\
d f(1) p=0.02\end{array}$ \\
\hline $\begin{array}{l}\text { Subjective global health } \\
(M V=1)\end{array}$ & & & & $\begin{array}{l}x^{2}=11.0 \\
d f(3), p=0.01\end{array}$ \\
\hline Very healthy & $63 / 321(19.6 \%)$ & Ref & Ref & \\
\hline Good & $51 / 269(18.9 \%)$ & $0.9(0.6-1.3)$ & $0.9(0.6-1.3)$ & \\
\hline Moderate & $27 / 126(21.4 \%)$ & $1.0(0.6-1.6)$ & $1.0(0.7-1.7)$ & \\
\hline Not very healthy & 13/31 (41.9\%) & $2.5(1.3-4.5)$ & $2.9(1.6-5.4)$ & \\
\hline $\begin{array}{l}\text { WHODAS } 12 \text { disability } \\
\text { score (per unit) }\end{array}$ & - & $1.023(1.015-1.030)$ & $1.024(1.015-1.032)$ & $\begin{array}{l}X^{2}=37.3 \\
d f(1) p<0.001\end{array}$ \\
\hline
\end{tabular}

1. MV = Number of missing values

Family Health Survey [9], in the study of older people in Wuhan, China [6], and with some research from developed countries [15]. It has been suggested that selective mortality in early life among those exposed to harsh eco- nomic deprivation, with only the fittest surviving to old age, may explain these findings [9]. The absence of any association with tobacco use is also consistent with Indian data suggesting an attenuation of effect in older 
Table 6: Cox Proportional Hazard predictors of mortality among older adult

\begin{tabular}{|c|c|c|c|c|}
\hline \multirow[b]{2}{*}{ Risk exposure } & \multicolumn{2}{|c|}{ Model 1} & \multicolumn{2}{|c|}{ Model 2} \\
\hline & $\begin{array}{l}\text { Hazard Ratio }(95 \% \mathrm{Cl}) \\
\text { adjusted for all variables } \\
\text { in the model } \\
(\mathrm{n}=727)\end{array}$ & $\begin{array}{c}\text { Adjusted Population } \\
\text { Attributable Risk } \\
\text { Fraction } \\
(95 \% \mathrm{Cl})\end{array}$ & $\begin{array}{l}\text { Hazard Ratio }(95 \% \mathrm{Cl}) \\
\text { adjusted for all variables } \\
\text { in the model } \\
(\mathrm{n}=726)\end{array}$ & $\begin{array}{c}\text { Adjusted Population } \\
\text { Attributable Risk } \\
\text { Fraction } \\
(95 \% \mathrm{Cl})\end{array}$ \\
\hline Male sex & $2.0(1.4-2.8)$ & $0.55(0.30-0.71)$ & $2.1(1.5-3.0)$ & $0.59(0.36-0.74)$ \\
\hline Arm circumference & $0.90(0.85-0.95)$ & $0.43(0.19-0.60)$ & $0.90(0.86-0.95)$ & $0.44(0.21-0.60)$ \\
\hline Age & & $0.45(0.27-0.59)$ & & $0.41(0.21-0.56)$ \\
\hline $65-69$ & 1 (ref) & & 1 (ref) & \\
\hline $70-74$ & $1.4(0.9-2.1)$ & & $1.4(0.9-3.6)$ & \\
\hline $75-79$ & $1.9(1.2-3.1)$ & & $1.7(1.1-2.8)$ & \\
\hline $80+$ & $2.7(1.7-1.7)$ & & $2.5(1.5-4.0)$ & \\
\hline $\begin{array}{l}\text { Cognitive Impairment/ } \\
\text { Dementia }\end{array}$ & & $0.10(0.06-0.13)$ & & $0.07(0.04-0.10)$ \\
\hline Cognitively healthy & 1 (ref) & & 1 (ref) & \\
\hline $\begin{array}{l}\text { Mild Cognitive } \\
\text { Impairment }\end{array}$ & $1.4(0.9-2.1)$ & & $1.7(0.8-3.6)$ & \\
\hline $\begin{array}{l}\text { CDR questionable } \\
\text { dementia }\end{array}$ & $1.9(1.2-3.1)$ & & $1.5(0.8-2.7)$ & \\
\hline CDR mild dementia & $3.2(1.6-6.4)$ & & $2.4(1.2-4.8)$ & \\
\hline WHODAS disability score & Not included & Not included & $1.02(1.01-1.03)$ & $0.21(0.14-0.28)$ \\
\hline $\begin{array}{l}\text { Total Population } \\
\text { Attributable risk fraction }\end{array}$ & - & $0.87(0.74-0.93)$ & - & $0.90(0.79-0.95)$ \\
\hline $\begin{array}{l}\text { Global test of proportional } \\
\text { hazards assumption }\end{array}$ & $\begin{array}{c}\text { Chi squared }=6.1,9 \mathrm{df} \\
p=0.73\end{array}$ & & $\begin{array}{c}\text { Chi squared }=7.1,10 \mathrm{df}, \\
p=0.72\end{array}$ & \\
\hline
\end{tabular}

people [46]. This finding may also be explained by selective mortality in earlier life. As noted in previous Indian research [10], and among older people in developed countries $[17,18]$ undernutrition (highly prevalent in India), as opposed to obesity (still relatively rare) was by far the more potent risk factor for mortality in our cohort.
Some of the independent risk factors identified in our study may be amenable to preventive interventions. Undernutrition among older people accounted independently for $44 \%$ of deaths, and, in principle, is a modifiable exposure. More research is required to understand whether the excess mortality is accounted for by low calorie intake or specific micronutrient deficiency, or both. 
There are as yet no data from India on the prevalence of iron, B12 and folate deficiency among older people, but anemia is highly prevalent [47]. Undernutrition may be associated with underhydration that could be an important cause of mortality during hot and dry spells. In India, dementia is seen as a normal part of ageing [48], but it is also stigmatized [49], and associated with carer psychological and economic strain [50,51]. Community medical services fail to meet the needs of older people with dementia, because of their focus upon acute 'treatable' conditions, their lack of outreach, and their inability to provide education and long-term support to family carers [52]. A pilot randomized controlled trial of a home-based carer education and support intervention for people with dementia in Goa substantially reduced carer strain and was associated with a marginally non-significant $66 \%$ reduction in mortality in the intervention arm (OR 0.34, 95\% CI 0.01-1.03) [53]. While dementia, among older people, is the major independent contributor to disability and dependency, comorbidity with other chronic physical and mental health conditions is the norm [54-56]. Thus, community-based interventions would be most efficiently incorporated into horizontal programs addressing the generic needs of frail, dependent older people and their carers, These could include attention to nutrition, hydration, immobility, behavioural disturbance, incontinence, sensory impairment, depression, hopelessness, and social isolation, whether arising from cognitive, mental or physical disorders, or a combination of these factors.

\section{Conclusions}

The current priority agenda for preventing deaths from chronic diseases in LMIC [57] may be less relevant to older people, who account for nearly three quarters of chronic disease deaths in these regions. A more balanced approach to prevention of chronic disease deaths requires some attention to proximal risk factors in older people. Smoking and obesity seem much less relevant than in younger people. Undernutrition is preventable. Dementia can be conveniently be addressed, along with other, often comorbid chronic diseases, through interventions targeting frail dependent older people. The development and evaluation of such packages of care should be considered as an urgent priority, consistent with the Madrid International Plan for Action on Ageing call for primary and secondary healthcare and long-term care to meet the needs of older persons, eliminating social and economic inequalities.

\section{List of abbreviations}

10/66 DRG: 10/66 Dementia Research Group; ADI: Alzheimer's Disease International; CDR: Clinical Demen- tia Rating; DSM-IV: Diagnostic and Statistical Manual of Mental Disorders, $4^{\text {th }}$ edition; ICD 10: International Classification of Diseases, 10th edition; IT: information technology; LMIC: low and middle income countries; MCI: Mild cognitive impairment; PARF: population attributable risk fraction; SMR: standardized mortality ratio; SD: standard deviation; Rs: Rupees (Indian); MV: Number of missing values; WHODAS 2.0: World Health Organization Disability assessment schedule, version 2.0

\section{Competing interests \\ The 10/66 Dementia Research Group works closely with Alzheimer's Disease International (ADI), the non-profit federation of 77 Alzheimer associations around the world. ADI is committed to strengthening Alzheimer associations worldwide, raising awareness regarding dementia and Alzheimer's Disease and advocating for more and better services for people with dementia and their caregivers. ADI is supported in part by grants from GlaxoSmithKline, Novartis, Lundbeck, Pfizer and Eisai}

\section{Authors' contributions}

The study was conceived and designed collectively by all of the authors. ATJ coordinated and conducted the field work for this study under the local supervision of JDW. ATJ and MJP conducted the analyses and wrote the first draft of this paper. All authors read and approved the final version.

\section{Acknowledgements}

This study was funded by the Wellcome Trust as a Health Consequences of Population Change Programme Master's level fellowship for A.T. Jotheeshwaran (GR081343). The baseline phase of the project was supported by the World Health Organization. The Rockefeller Foundation supported our dissemination meeting at their Bellagio Centre. Alzheimer's Disease International has provided support for networking and infrastructure.

\section{Author Details}

1'Institute of Community Health, Voluntary Health Services, Chennai, India and ${ }^{2}$ Centre for Global Mental Health, Health Service and Population Research Department, Institute of Psychiatry, P060, De Crespigny Park, London SE5 8AF, UK

Received: 14 November 2009 Accepted: 23 June 2010

Published: 23 June 2010

\section{References}

1. Sibai AM: Mortality certification and cause-of-death reporting in developing countries. Bull World Health Organ 2004, 82:83.

2. World Health Organization: The global burden of disease. 2004 update Geneva: World Health Organization; 2008.

3. World Health Organization: WHO Statistical Information System. Working paper describing data sources, methods and results for projections of mortality and burden of disease for 2005, 2015 and 20302006.

4. Horton R: The neglected epidemic of chronic disease. Lancet 2005, 366:1514

5. Horton R: Chronic diseases: the case for urgent global action. Lancet 2007, 370:1881-1882.

6. Liang J, McCarthy JF, Jain A, Krause N, Bennett JM, Gu S: Socioeconomic gradient in old age mortality in Wuhan, China. $J$ Gerontol B Psychol Sci Soc Sci 2000, 55:S222-S233.

7. Suh GH: Predictors of mortality in an aging community-based cohort in Korea. Psychogeriatrics 2006, 6:10-18.

8. Mostafa G, van Ginneken JK: Trends in and determinants of mortality in the elderly population of Matlab, Bangladesh. Soc Sci Med 2000, 50:763-771

9. Subramanian SV, Nandy S, Irving M, Gordon D, Lambert H, Davey SG: The mortality divide in India: the differential contributions of gender, caste, and standard of living across the life course. Am J Public Health 2006, 96:818-825.

10. Pednekar MS, Gupta PC, Hebert JR, Hakama M: Joint effects of tobacco use and body mass on all-cause mortality in Mumbai, India: results 
from a population-based cohort study. Am J Epidemiol 2008, 167:330-340

11. Gupta PC, Mehta HC: Cohort study of all-cause mortality among tobacco users in Mumbai, India. Bulletin of the World Health Organization 2000, 78:877-883.

12. Marmot M, Ryff CD, Bumpass LL, Shipley M, Marks NF: Social inequalities in health: Next questions and converging evidence. Social Science \& Medicine 1997, 44:901-910.

13. Elo IT, Preston SH: Educational differentials in mortality: United States, 1979-85. Social Science \& Medicine 1996, 42:47-57.

14. Sorlie PD, Backlund E, Keller JB: US mortality by economic, demographic, and social characteristics: the National Longitudinal Mortality Study.[see comment]. American Journal of Public Health 1995 85:949-956.

15. Goldblatt P: Mortality and the social classification of women. In Longitudinal Study: Mortality and Social Organization Edited by: Goldblatt P. London: HMSO; 1990:145-162.

16. Haveman-Nies A, de Groot LP, Burema J, Cruz JA, Osler M, van Staveren WA: Dietary quality and lifestyle factors in relation to 10 -year mortality in older Europeans: the SENECA study. Am J Epidemiol 2002, 156:962-968.

17. Pitner JK: Obesity in the elderly. Consult Pharm 2005, 20:498-513.

18. Tajima O, Nagura E, Ishikawa-Takata K, Ohta T: Two new potent and convenient predictors of mortality in older nursing home residents in Japan. Geriatrics and Gerontology International 2004, 4:77-83.

19. Grabowski DC, Ellis JE: High body mass index does not predict mortality in older people: analysis of the Longitudinal Study of Aging. J Am Geriatr Soc 2001, 49:968-979.

20. Cuijpers P, Smit F: Excess mortality in depression: a meta-analysis of community studies. Journal of Affective Disorders 2002, 72:227-236.

21. Dewey ME, Saz P: Dementia, cognitive impairment and mortality in persons aged 65 and over living in the community: a systematic review of the literature. International Journal of Geriatric Psychiatry 2001, 16:751-761

22. Ostbye T, Hill G, Steenhuis R: Mortality in elderly Canadians with and without dementia: a 5-year follow-up. Neurology 1999, 53:521-526.

23. Nitrini R, Caramelli P, Herrera E Jr, de C, Bahia VS, Anghinah R, Caixeta LF, Radanovic M, Charchat-Fichman H, Porto CS, Teresa CM, Hartmann AP, Huang N, Smid J, Lima EP, Takahashi DY, Takada LT: Mortality from dementia in a community-dwelling Brazilian population. International Journal of Geriatric Psychiatry 2005, 20:247-253.

24. Perkins AJ, Hui SL, Ogunniyi A, Gureje O, Baiyewu O, Unverzagt FW, Gao S, Hall KS, Musick BS, Hendrie, et al:: Risk of mortality for dementia in a developing country: the Yoruba in Nigeria. International Journal of Geriatric Psychiatry 2002, 17:566-573.

25. Ceria CD, Masaki KH, Rodriguez BL, Chen R, Yano K, Curb JD: The relationship of psychosocial factors to total mortality among older Japanese-American men: the Honolulu Heart Program. Journal of the American Geriatrics Society 2001, 49:725-731.

26. Sugisawa H, Liang J, Liu X: Social networks, social support, and mortality among older people in Japan. J Gerontol 1994, 49:S3-13.

27. House JS, Robbins C, Metzner HL: The association of social relationships and activities with mortality: prospective evidence from the Tecumseh Community Health Study. Am J Epidemiol 1982, 116:123-140

28. Penninx BW, van TT, Kriegsman DM, Deeg DJ, Boeke AJ, van Eijk JT: Effects of social support and personal coping resources on mortality in older age: the Longitudinal Aging Study Amsterdam. Am J Epidemiol 1997. 146:510-519.

29. Ganguli M, Dodge HH, Mulsant BH: Rates and predictors of mortality in an aging, rural, community-based cohort: the role of depression. Archives of General Psychiatry 2002, 59:1046-1052.

30. Maier H, Smith J: Psychological predictors of mortality in old age. Journals of Gerontology Series B-Psychological Sciences \& Social Sciences 1999, 54:44-54

31. Iwasa H, Kawaai C, Gondo Y, Inagaki H, Suzuki T: Subjective well-being as a predictor of all-cause mortality among middle-aged and elderly people living in an urban Japanese community: A seven-year prospective cohort study. [References]. Geriatrics \& Gerontology International 2006, 6:216-222.

32. Frisoni GB, Fratiglioni L, Fastbom J, Viitanen M, Winblad B: Mortality in nondemented subjects with cognitive impairment: the influence of health-related factors. American Journal of Epidemiology 1999, 150:1031-1044

33. Blazer DG, Hybels CF, Pieper CF: The association of depression and mortality in elderly persons: a case for multiple, independent pathways. J Gerontol A Biol Sci Med Sci 2001, 56:M505-M509.

34. Prince M, Ferri CP, Acosta D, Albanese E, Arizaga R, Dewey M, Gavrilova SI, Guerra M, Huang Y, Jacob KS, Krishnamoorthy ES, McKeigue P, Rodrigues JL, Salas A, Sosa AL, Sousa R, Stewart R, Uwakwe R: The protocols for the 10/66 Dementia Research Group population-based research programme. BMC Public Health 2007, 7:165.

35. Prince M, Acosta D, Chiu H, Scazufca M, Varghese M: Dementia diagnosis in developing countries: a cross-cultural validation study. Lancet 2003, 361:909-917.

36. American Psychiatric Association: Diagnostic and Statistical Manual of Mental Disorders 4th edition. Washington DC: AMA; 1994.

37. Morris JC: The Clinical Dementia Rating (CDR): current version and scoring rules [see comments]. Neurology 1993, 43:2412-2414.

38. Winblad B, Palmer K, Kivipelto M, Jelic V, Fratiglioni L, Wahlund LO, Nordberg A, Backman L, Albert M, Almkvist O, Arai H, Basun H, Blennow K, de LM, DeCarli C, Erkinjuntti T, Giacobini E, Graff C, Hardy J, Jack C, Jorm A, Ritchie K, van DC, Visser P, Petersen RC: Mild cognitive impairment-beyond controversies, towards a consensus: report of the International Working Group on Mild Cognitive Impairment. J Intern Med 2004, 256:240-246.

39. Copeland JRM, Dewey ME, Griffith-Jones HM: A computerised psychiatric diagnostic system and case nomenclature for elderly subjects: GMS and AGECAT. Psychological Medicine 1986, 16:89-99.

40. Prince MJ, Reischies F, Beekman ATF, Fuhrer R, Hooijer C, Kivela S, Lawlor B, Lobo A, Magnusson H, Meller I, Skoog I, Turrina C, Copeland JRM: The development of the EURO-D scale - A European Union initiative to compare symptoms of depression in 14 European centres. British Journal of Psychiatry 1999, 174:330-338.

41. George LK, Fillenbaum GG: OARS methodology: A decade of experience in geriatric assessment. Journal of the American Geriatrics Society 1985:607-615

42. Rehm J, Ustun TB, Saxena S: On the development and psychometric testing of the WHO screening instrument to assess disablement in the general population. International Journal of Methods in Psychiatric Research 2000, 8:110-122.

43. Sample Registration System RGI: Estimated age (by sex) specific death rates in India 1999. 20102009 [http://cbhidghs.nic.in/Hiii2000-01/2.09.htm].

44. CDC: Number of deaths and death rates, by age, race, and sex: United States, 20052010 [http://www.disastercenter.com/cdc/Death rates 2005.html]. accessed April 2009

45. Gajalakshmi V, Peto R, Kanaka S, Balasubramanian S: Verbal autopsy of 48 000 adult deaths attributable to medical causes in Chennai (formerly Madras), India. BMC Public Health 2002, 2:7.

46. Gupta PC, Pednekar MS, Parkin DM, Sankaranarayanan R: Tobacco associated mortality in Mumbai (Bombay) India. Results of the Bombay Cohort Study. Int J Epidemio/ 2005, 34:1395-1402.

47. Singh PM, Anita P, Vedpal D: Prevalence of anemia in an elderly rural population of northern India. J Am Geriatr Soc 2009, 57:355-357.

48. Patel V, Prince M: Ageing and mental health in a developing country: who cares? Qualitative studies from Goa, India. Psychological Medicine 2001, 31:29-38

49. Ferri $C P$, Ames $D$, Prince $M$ : Behavioral and psychological symptoms of dementia in developing countries. Int Psychogeriatr 2004, 16:441-459.

50. Dias A, Samuel R, Patel V, Prince M, Parameshwaran R, Krishnamoorthy ES: The impact associated with caring for a person with dementia: a report from the 10/66 Dementia Research Group's Indian network. Int J Geriatr Psychiatry 2004, 19:182-184.

51. Prince $\mathrm{M}$ : Care arrangements for people with dementia in developing countries. Int J Geriatr Psychiatry 2004, 19:170-177.

52. Prince $M$, Livingston $G$, Katona $C$ : Mental health care for the elderly in low-income countries: a health systems approach. World Psychiatry 2007, 6:5-13.

53. Dias A, Dewey ME, D'Souza J, Dhume R, Motghare DD, Shaji KS, Menon R, Prince $M$, Patel V: The effectiveness of a home care program for supporting caregivers of persons with dementia in developing countries: a randomised controlled trial from Goa, India. PLOS ONE 2008, 3:e2333. 
54. Acosta D, Rottbeck R, Rodriguez G, Ferri CP, Prince MJ: The epidemiology of dependency among urban-dwelling older people in the Dominican Republic; a cross-sectional survey. BMC Public Health 2008, 8:285.

55. Uwakwe R, Ibeh CC, Modebe Al, Bo E, Ezeama N, Njelita I, Ferri CP, Prince

MJ: The Epidemiology of Dependence in Older People in Nigeria:

Prevalence, Determinants, Informal Care, and Health Service

Utilization. A 10/66 Dementia Research Group Cross-Sectional Survey. J Am Geriatr Soc 2009.

56. Sousa RM, Ferri CP, Acosta D, Albanese E, Guerra M, Huang Y, Jacob KS, Jotheeswaran AT, Rodriguez JJ, Pichardo GR, Rodriguez MC, Salas A, Sosa AL, Williams J, Zuniga T, Prince M: Contribution of chronic diseases to disability in elderly people in countries with low and middle incomes: a 10/66 Dementia Research Group population-based survey. Lancet 2009, 374:1821-1830.

57. Beaglehole R, Ebrahim S, Reddy S, Voute J, Leeder S: Prevention of chronic diseases: a call to action. Lancet 2007, 370:2152-2157.

\section{Pre-publication history}

The pre-publication history for this paper can be accessed here: http://www.biomedcentral.com/1471-2458/10/366/prepub

\section{doi: 10.1186/1471-2458-10-366}

Cite this article as: Jotheeswaran et al., Predictors of mortality among elderly people living in a south Indian urban community; a 10/66 Dementia Research Group prospective population-based cohort study BMC Public Health 2010, 10:366

Submit your next manuscript to BioMed Central and take full advantage of:

- Convenient online submission

- Thorough peer review

- No space constraints or color figure charges

- Immediate publication on acceptance

- Inclusion in PubMed, CAS, Scopus and Google Scholar

- Research which is freely available for redistribution 